\title{
Human LYPD8 protein inhibits motility of flagellated bacteria
}

Chiao-Ching Hsu ${ }^{1,2,3}$, Ryu Okumura ${ }^{1,2,3}$ and Kiyoshi Takeda ${ }^{1,2,3^{*}}$

\begin{abstract}
Background: We previously reported that the mouse Ly6/Plaur domain containing 8 (mLypd8), a GPI-anchored protein highly and selectively expressed on colonic epithelia, contributes to segregation of intestinal microbiota and intestinal epithelia and is critical for prevention of intestinal inflammation. In addition, it was found that human LYPD8 (hLYPD8) is expressed in the colonic epithelia and expression of hLYPD8 is reduced in some ulcerative colitis patients. However, the molecular characteristics and functions of hLYPD8 remain unclear. In this study, we generated the hLYPD8 protein and characterized its functions.

Methods: To analyze the characteristics and functions of the hLYPD8 protein, recombinant FLAG-tagged hLYPD8 protein was generated by two kinds of protein expression systems: a mammalian cell expression system and a Pichia pastoris expression system. Recombinant hLYPD8 protein was analyzed by western blot analysis or deglycosylation assay. The effect of the protein on flagellated bacteria was examined by ELISA assay and motility assay using semi-agar plates.

Results: hLYPD8 was a highly N-glycosylated GPI-anchored protein, like mLypd8. Moreover, recombinant hLYPD8 protein generated by the Pichia pastoris expression system using the SuperMan ${ }_{5}$ strain, which enabled production of a large number of proteins with human-like glycosylation, presented the high binding affinity and the motility inhibitory function to flagellated bacteria, such as Proteus mirabilis.

Conclusions: These results demonstrated that hLYPD8 inhibits the motile activity of flagellated bacteria, many of which are involved in intestinal inflammation. The supplementation of recombinant hLYPD8 protein might be a novel therapeutic approach for intestinal inflammation of inflammatory bowel diseases.
\end{abstract}

Keywords: LYPD8, Glycosylation, Pichia Pastoris, Flagellated bacteria, Intestinal inflammation

\section{Background}

Intestinal epithelial cells play important roles in the regulation of intestinal inflammation by generating several kinds of mucosal barriers, including mucus and antimicrobial peptides. These barriers contribute to the segregation of intestinal bacteria and the intestinal mucosa, which is indispensable for homeostatic maintenance of the gut where tremendous numbers of microorganisms live symbiotically [1-5]. Therefore, the dysfunction of mucosal barriers leads to the excessive immune response in the intestinal mucosa, which causes

\footnotetext{
* Correspondence: ktakeda@ongene.med.osaka-u.ac.jp

'Department of Microbiology and Immunology, Graduate School of

Medicine, Osaka University, Osaka 565-0871, Japan

WPI Immunology Frontier Research Center, Osaka University, Osaka

565-0871, Japan

Full list of author information is available at the end of the article
}

inflammatory bowel disease (IBD) represented by ulcerative colitis (UC) and Crohn's disease (CD) [6]. Indeed, it has been reported that increased intestinal permeability and penetration of intestinal bacteria into the mucus layer due to barrier dysfunction are found in the intestine of IBD patients $[7,8]$.

In the colon, where tremendous numbers of microorganisms exist, intestinal microbiota and intestinal epithelial cells are clearly segregated by the thick mucus layer to maintain the symbiotic relationship between commensal microorganisms and the host [2, 3]. We previously demonstrated that the Ly6/Plaur domain containing 8 (Lypd8) expressed in intestinal epithelial cells promotes the segregation of intestinal bacteria and epithelial cells in the colon [9]. This molecule is an $\mathrm{N}$ glycosylated GPI-anchored protein, and it binds to 
flagella and suppresses the motility of flagellated bacteria to prevent bacterial invasion of colonic mucosa. Furthermore, it was found that human LYPD8 (hLYPD8) is also expressed in the colonic epithelia, and the expression of LYPD8 is reduced in the colon of some UC patients. However, the molecular characteristics and functions of hLYPD8 remain unclear. We therefore analyzed the molecular characteristics and function of recombinant hLYPD8 protein generated by both mammalian cellexpression system and Pichia pastoris expression system.

\section{Methods}

\section{Generation of HEK293T cells stably expressing mLypd8} and hLYPD8

Mouse Lypd8 (mLypd8) and human LYPD8 (hLYPD8) genes were amplified by PCR from mouse and human colonic cDNA. A FLAG-tagged sequence was inserted into the total mLypd8 and hLYPD8 coding sequence immediately downstream of the predicted N-terminal signal sequence. HEK293T cells obtained from ATCC were transfected with linearized pcDNA3.1 $(+)$ vector (Invitrogen) inserted the sequence for FLAG-tagged mLypd8 or hLYPD8 using Lipofectamine2000 (Invitrogen). These cells were cultured in G418-containing medium. The surviving cells were stained with anti-FLAG M2 monoclonal antibody (cat F3165: Sigma-Aldrich) and Alexa Fluor 488 goat anti-mouse IgG antibody (cat A11001: Molecular Probes), and cells expressing FLAG-tagged mLypd8 or hLYPD8 were sorted using FACSAria (BD Biosciences).

\section{Purification of FLAG-tagged hLYPD8 proteins from HEK293T cells}

Recombinant hLYPD8 protein was purified from HEK293T cells stably expressing FLAG-tagged hLYPD8 using FLAG M2 Purification Kit (Sigma-Aldrich). As a negative control, non-transfected cells were used.

\section{Assay for GPI cleaving activity}

HEK293T cells stably expressing hLYPD8 $\left(1 \times 10^{6}\right.$ cells $)$ were rinsed twice with cold PBS and incubated with $0.5 \mathrm{ml}$ of PBS containing 0.5 units of Bacillus cereus phosphatidylinositol-specific phospholipase C (PI-PLC, Molecular Probes) at $4{ }^{\circ} \mathrm{C}$ for $20 \mathrm{~min}$. These cells were stained with anti-FLAG M2 mAb (Sigma-Aldrich) and Alexa Fluor 488 goat anti-mouse IgG (Invitrogen). The surface expression of hLYPD8 was analyzed using FACSCanto II (BD Biosciences).

\section{Deglycosylation assay}

Recombinant hLYPD8 protein $(1 \mu \mathrm{g})$ was incubated with PNGase F, sialidase A, and $\mathrm{O}$-glycanase (Prozyme) at
$37{ }^{\circ} \mathrm{C}$ for $3 \mathrm{~h}$. Recombinant hLYPD8 protein treated with glycanase was separated with SDS-PAGE and transferred to polyvinylidene fluoride membranes (Millipore) that were incubated with horseradish peroxidase (HRP)conjugated anti-FLAG M2 mAb (Sigma-Aldrich). Immunoreactivity was detected using Chemi-Lumi One (Nacalai Tesque).

\section{ELISA assay of LYPD8 binding to bacteria}

Bacterial strains including Escherichia coli JCM $1649^{\mathrm{T}}$, Enterococcus gallinarum JCM $8728^{\mathrm{T}}$, Bacteroides sartrii JCM $17136^{\mathrm{T}}$, and Bifidobacterium breve JCM $1192^{\mathrm{T}}$ were obtained from the Japan Collection of Microorganisms. Proteus mirabilis was isolated from the colonic tissue of $L y p d 8^{-1-}$ mice as described previously [9]. These bacteria were cultured at $37{ }^{\circ} \mathrm{C}$ for $16 \mathrm{~h}$ in an anaerobic chamber, fixed by $4 \%$ PFA, and stained with DAPI. The cell numbers were quantified by a confocal microscope. Each bacterium was centrifuged at $5000 \times g$ for $5 \mathrm{~min}$, and the pellet was resuspended in $0.05 \mathrm{M}$ sodium carbonate. The bacteria $\left(1 \times 10^{7}\right.$ cells/ ml $)$ were coated on 96-well plates (Corning) and incubated for $16 \mathrm{~h}$ at $4{ }^{\circ} \mathrm{C}$. The plates were then washed with PBS and blocked with $1 \%$ BSA/PBS. After the plates were washed, the increasing concentrations of FLAG-tagged hLYPD8 protein diluted in PBS were added and incubated for $2 \mathrm{~h}$ at room temperature. Next, after the plates were washed, HRP-conjugated anti-FLAG M2 mAb (Sigma-Aldrich) in PBS was added and incubated for $1 \mathrm{~h}$ at room temperature. The plates were then washed, and 3,3',5,5' -tetramethylbenzidine (TMB) substrate was added. Stop solution $1 \mathrm{M} \mathrm{H}_{2} \mathrm{SO}_{4}$ was then added, and the plates were read at $450 \mathrm{~nm}$ with a spectrometer.

\section{Pull-down assay for LYPD8 binding to flagella}

Bacterial suspension of $P$. mirabilis or E. coli JCM $1649^{\mathrm{T}}$ in PBS was shaken 300 times per min for $60 \mathrm{~min}$ to remove flagella from bacterial bodies. Bacterial bodies were pelleted by centrifuging at $4000 \times g$ for $20 \mathrm{~min}$. The supernatants were ultracentrifuged at $80,000 \times g$ for $60 \mathrm{~min}$ to obtain flagella. Bacterial bodies or flagella were mixed with the solu-

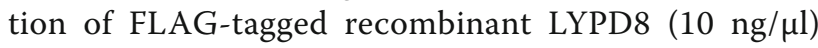
and incubated for $3 \mathrm{~h}$ at $4{ }^{\circ} \mathrm{C}$. After incubation, the bacterial bodies or flagella were pelleted down by centrifugation or ultracentrifugation, respectively. Then, the supernatant was collected and the pellet was resuspended in PBS. The supernatant and pellet suspension were separated with SDS-PAGE and transferred to polyvinylidene fluoride membranes (Millipore) that were incubated with HRP-conjugated anti-FLAG M2 mAb (Sigma-Aldrich). Immunoreactivity was detected using Chemi-Lumi One (Nacalai Tesque). 


\section{Generation of Pichia pastoris expressing glycosylated hLYPD8 protein}

The host strain Pichia pastoris SuperMan ${ }_{5}$ strain $\left(\right.$ HIS $\left.^{+}\right)$ and the expression vector pJAZ-aMF vector were purchased from Biogrammatics Inc. (Carlsbad, USA). The FLAG-tagged LYPD8 gene without C-terminal signal sequence was amplified by PCR and ligated into pJAZaMF vector.

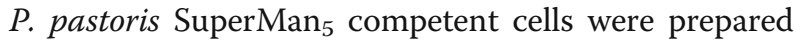
by a high-efficiency transformation condition suggested by $\mathrm{Wu}$ et al. [10]. Adequate amounts of constructed plasmids were digested with Pme I or Sac I to linear form and purified, then added to $P$. pastoris competent cells and well mixed. The mixed sample was added into a 2-mm gap cuvette (Bio-Rad, USA) and placed on ice for $5 \mathrm{~min}$. The linearized DNA fragment was transformed into $P$. pastoris competent cells by the electroporation condition of $1.5 \mathrm{kV}, 25 \mu \mathrm{F}$, and $200 \Omega$. Then, $1 \mathrm{ml}$ of $1 \mathrm{M}$ sorbitol was added into the sample and incubated at $30{ }^{\circ} \mathrm{C}$ for $1 \mathrm{~h}$. At last, the sample was poured evenly into YPDSZ (1\% yeast extract, $2 \%$ peptone, $2 \%$ dextrose, $1 \mathrm{M}$ sorbitol, $100 \mu \mathrm{g} / \mathrm{mL}$ zeocin) agar plates then cultured at $30{ }^{\circ} \mathrm{C}$ for $2-3$ days. Fifty colonies were selected to the new YPDZ agar plates with different zeocin gradients $(100,300$, and $500 \mu \mathrm{g} / \mathrm{ml})$ for testing the zeocin resistance and cultured at $30{ }^{\circ} \mathrm{C}$ for $1-2$ days. Few transformants with better zeocin resistance were selected for further analysis.

\section{Purification of FLAG-tagged hLYPD8 proteins generated by a Pichia pastoris expression system}

The selected transformants were inoculated in $4 \mathrm{ml}$ of YPDZ for $24 \mathrm{~h}$ as a seed culture, then transferred into $500 \mathrm{ml}$ BMGY (1\% yeast extract, 2\% peptone, $\mathrm{pH} 6.0$ $100 \mathrm{mM}$ potassium phosphate, $1 \%$ glycerol, $1.34 \%$ yeast nitrogen base, and $4 \times 10^{-5} \%$ biotin) and cultured at $30^{\circ}$ $\mathrm{C}, 200 \mathrm{rpm}$ for $24 \mathrm{~h}$. The medium of each transformant was replaced with $100 \mathrm{ml}$ of BMMY (1\% yeast extract, $2 \%$ peptone, $\mathrm{pH} 6.0100 \mathrm{mM}$ potassium phosphate, $1.34 \%$ yeast nitrogen base, $2 \%$ methanol, and $4 \times 10^{-5} \%$ biotin). The transformants were then cultured for $48 \mathrm{~h}$ at $20{ }^{\circ} \mathrm{C}, 200 \mathrm{rpm}$. At the 24 -h time point, $2 \%$ methanol $(2 \mathrm{ml})$ was added to the culture. Soluble FLAG-tagged hLYPD8 protein was purified from $100 \mathrm{ml}$ of the supernatant by column chromatography according to the FLAG M2 Purification Kit (Sigma-Aldrich).

\section{Motility assay of Proteus mirabilis and Escherichia coli in semisolid agar}

HEK293T cells $\left(5 \times 10^{7}\right.$ cells $)$ with or without FLAGtagged hLYPD8 were lysed with $1 \mathrm{ml}$ of CelLytic M Cell Lysis Reagent (Sigma-Aldrich). After centrifuging at $13,000 \times g$ for $10 \mathrm{~min}$, the supernatant was incubated with $150 \mu \mathrm{l}$ of anti-FLAG M2 affinity gel (Sigma-Aldrich) for
3 h. The resin was centrifuged and washed with Trisbuffered saline three times. The resin containing FLAGtagged hLYPD8 was mixed with $2 \mathrm{ml}$ of lysogeny broth (LB) medium containing $0.3 \%$ agar. The final concentration of hLYPD8 protein in the LB agar was estimated by SDS-PAGE and was approximately $1.5 \mu \mathrm{g} / \mathrm{ml}$. In the case of usage of soluble hLYPD8 protein generated by $P$. pastoris, $0.5 \mathrm{ml}$ of recombinant soluble hLYPD8 protein was mixed with $1.5 \mathrm{ml}$ of the LB medium containing $0.3 \%$ agar. The final concentration of hLYPD8 protein in the LB agar was estimated by SDS-PAGE and BCA assay, and it was approximately $50 \mu \mathrm{g} / \mathrm{ml}$.

$P$. mirabilis or $E$. coli was cultured in the LB medium at $37{ }^{\circ} \mathrm{C}$ until $\mathrm{OD}_{600}$ was 0.6 . The semisolid LB agar $(0.3 \%)$ containing hLYPD8 protein was centrally inoculated with $1 \mu \mathrm{l}$ of bacterial culture and incubated at $37{ }^{\circ} \mathrm{C}$. Motility was assessed by examining circular migration. The radius of circles formed by bacterial migration was measured at $4 \mathrm{~h}$ after the bacterial inoculation.

\section{ELISA assay for LYPD8 binding to flagella}

Several 96-well plates (Corning) were coated with $100 \mu \mathrm{g} /$ $\mathrm{ml}$ flagella of $P$. mirabilis or $1 \% \mathrm{BSA} / \mathrm{PBS}$ for $16 \mathrm{~h}$ at $4{ }^{\circ} \mathrm{C}$. The plates were then washed, and increasing concentrations of FLAG-tagged hLYPD8 protein diluted in 1\% BSA/ PBS were added and incubated for $2 \mathrm{~h}$ at room temperature. The plates were then washed, and HRPconjugated anti-FLAG M2 mAb (Sigma-Aldrich) diluted in $1 \% \mathrm{BSA} / \mathrm{PBS}$ was added and incubated for $2 \mathrm{~h}$ at room temperature. The plates were then washed, and TMB substrate was added. The plates were then read at $450 \mathrm{~nm}$ with a spectrometer.

\section{Statistical analysis}

Data are presented as mean \pm s.d., as indicated in the figure legends. Differences between control and experimental groups were evaluated using a two-tailed unpaired Student's $t$ test. A $P$ value of $<0.05$ was considered significant. No statistical methods were used to predetermine sample size. No sample was excluded from the analysis.

\section{Results}

\section{Molecular characteristics of the hLYPD8 protein}

LYPD8 is broadly conserved in mammalian species, including human, mouse, and rat. We previously showed that mouse Lypd8 (mLypd8) is a highly $N$-glycosylated protein. The hLYPD8 protein also contains eight glycosylation sites predicted by the amino acid sequence (Fig. 1a). We first purified recombinant hLYPD8 protein from HEK293T cells stably expressing FLAG-tagged hLYPD8 and analyzed the protein by SDS-PAGE and western blot analysis. Although the expected molecular weight from amino acid length is about $20 \mathrm{kDa}$, a band 

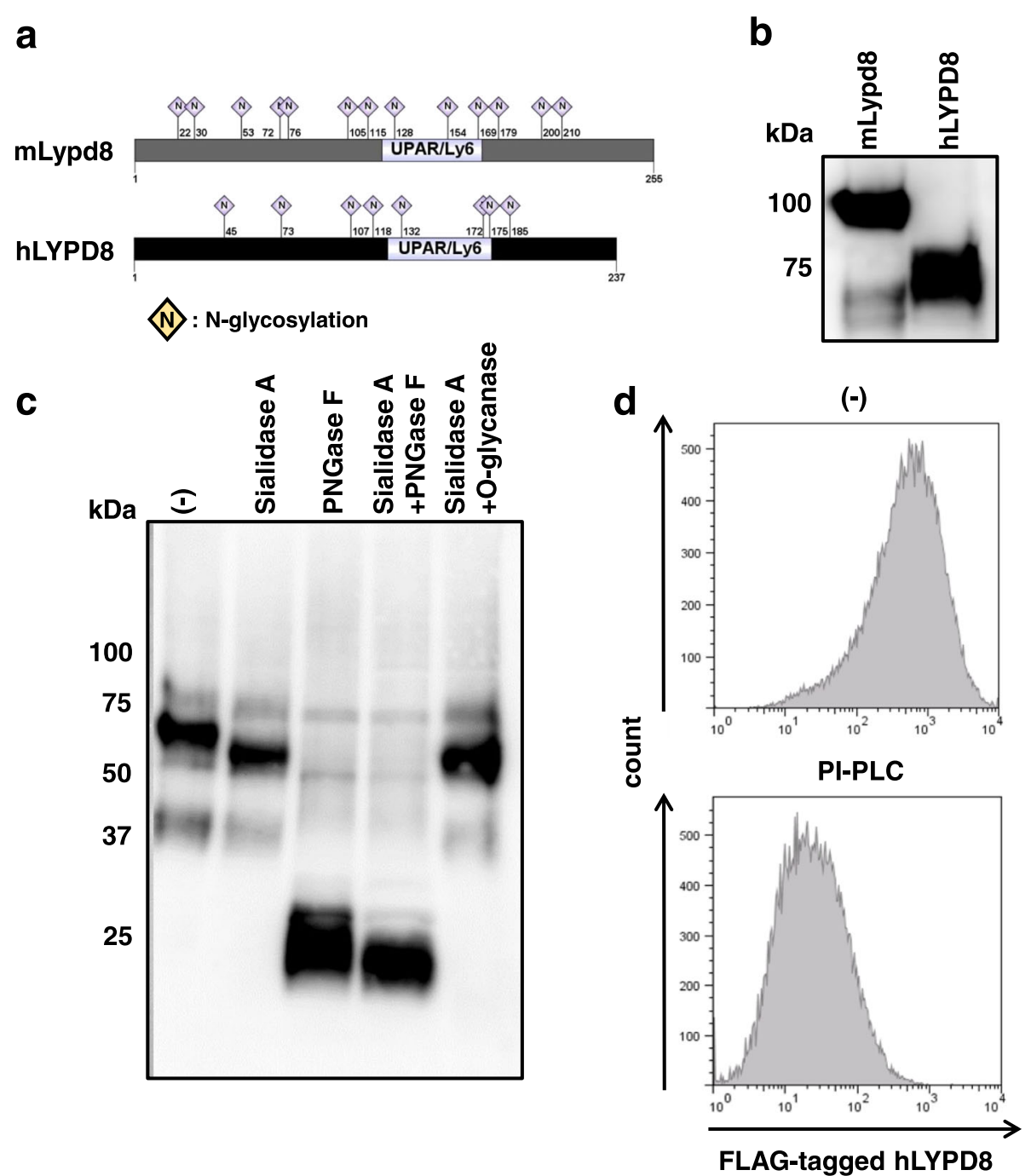

Fig. 1 Molecular characteristics of the hLYPD8 protein. a Predicted glycosylation sites of the mLypd8 and hLYPD8 proteins. Glycosylation sites were referred to the UniProt database, and the picture was drawn by a group-based predictive system (IBS 1.0.2). b Immunoblotting for whole cell lysates of HEK293T cells expressing mLypd8 and hLYPD8. c Immunoblotting for recombinant hLYPD8 protein untreated or treated with sialidase A, PNGase F, or O-glycanase. d Flow cytometric analysis of HEK239T cells expressing FLAG-tagged LYPD8 before (upper) and after (lower) treatment with PI-PLC

for recombinant hLYPD8 protein was observed at about the $75-\mathrm{kDa}$ position (Fig. 1b). In addition, the treatment with peptide-N-glycosidase F (PNGase F), which cleaves $N$-oligosaccharide chains from glycoproteins, substantially reduced the molecular weight of the hLYPD8 protein. In contrast, treatment with sialidase A and $O$ glycanase did not markedly change the molecular weight of the hLYPD8 protein (Fig. 1c). These data indicate that hLYPD8 is a highly $N$-glycosylated protein, like mLypd8. We next treated HEK293T cells expressing FLAGtagged hLYPD8 with phosphatidylinositol-phospholipase C (PI-PLC), which cleaves GPI-anchored proteins from the cell membrane, and analyzed hLYPD8 surface expression by flow cytometry. Treatment of PI-PLC severely reduced hLYPD8 surface expression, indicating that hLYPD8 is a GPI-anchored protein, similar to mLypd8 (Fig. 1d).

\section{Functions of the hLYPD8 protein generated by a mammalian cell expression system}

The molecular characteristics of hLYPD8 are similar to those of mLypd8. Therefore, we next investigated the functions of recombinant hLYPD8 protein generated by a mammalian cell expression system. In the previous study, the mLypd8 protein was found to preferentially bind to flagellated bacteria, such as $E$. coli and P. mirabilis. Hence, we examined whether the hLYPD8 protein produced in mammalian cells 
bind to various kinds of intestinal bacteria including P. mirabilis, E. coli, E. gallinarum, B. sartrii, and B. breve by an ELISA assay (Fig. 2a). The hLYPD8 protein preferentially bound to $E$. coli and $P$. mirabilis, both of which are flagellated bacteria. Next, isolated flagella and bacterial bodies from cultured $P$. mirabilis were incubated with the hLYPD8 protein and then pelleted down by centrifuging. The hLYPD8 protein and the flagella were coprecipitated (Fig. 2b). After incubation with increasing flagella concentration, the amount of the hLYPD8 protein in the supernatants was decreased, whereas it was increased in the pellets (Fig. 2c). The incubation with bacterial bodies did not alter the amount of hLYPD8 in the supernatants (Fig. 2d). These data indicate that the hLYPD8 protein binds to flagella of $P$. mirabilis. Therefore, we tested whether recombinant hLYPD8 protein inhibits the motile activity of $P$. mirabilis in a semi-agar plate. The swarm circle diameter was reduced in the semiagar plate containing the hLYPD8 protein (Fig. 2e, $\mathrm{f}$ ), indicating that the hLYPD8 protein inhibits the swarming motility of $P$. mirabilis, as does the mLypd8 protein.

\section{Generation of the hLYPD8 protein by a Pichia pastoris expression system}

To extensively explore the functions of hLYPD8, a high quantity and quality of recombinant hLYPD 8 protein are required. Considering the limitation of the proteinexpressing ability of mammalian cells, we established another recombinant protein expression system for

\section{a}

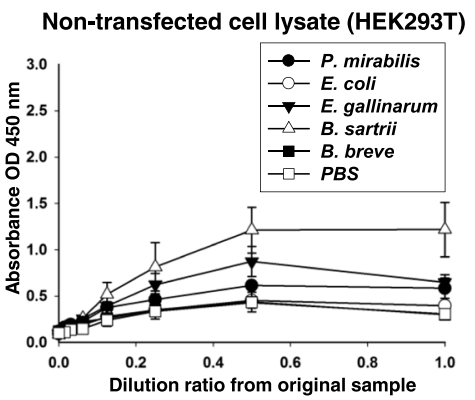

Recombinant LYPD8 (HEK293T)

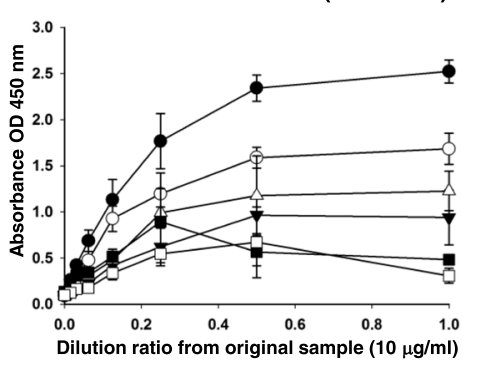

e

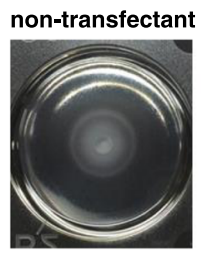

\section{LYPD8}

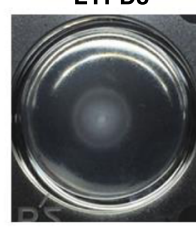

b
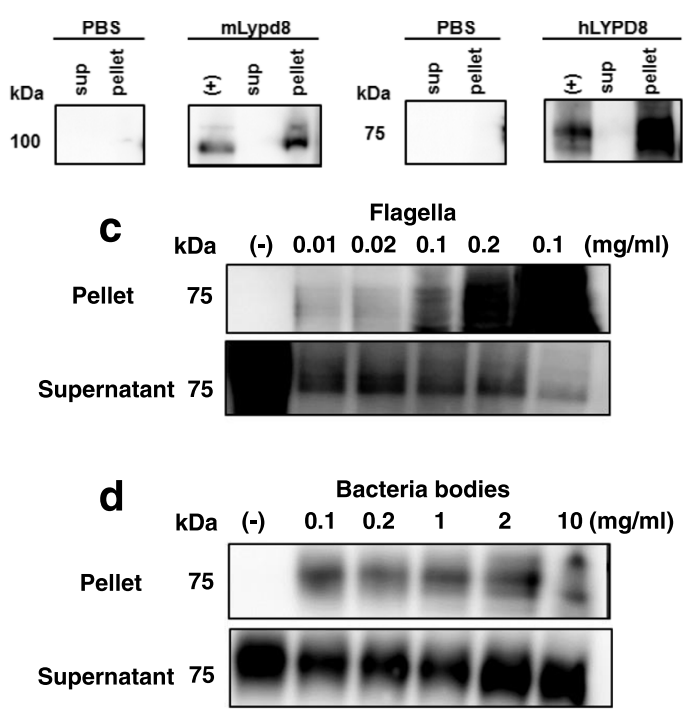

f

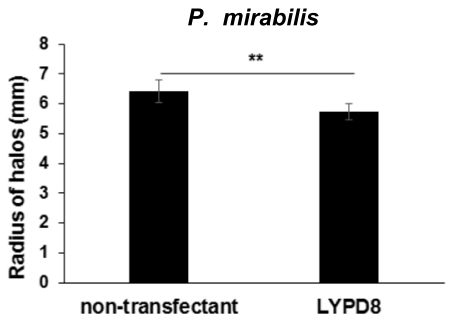

Fig. 2 Function of the hLYPD8 protein generated by a mammalian cell expression system. a ELISA assay for hLYPD8 binding to intestinal bacteria. The quantified bacteria were coated onto microtiter plates and incubated with a dilution series of purified FLAG-tagged hLYPD8 (lower) or control sample (purified sample of non-transfected HEK293T cell lysate) (upper). b-d Immunoblot analysis with the anti-FLAG antibody for the supernatant and pellet of the mixture of FLAG-tagged mLypd8 or hLYPD8 and flagella from P. mirabilis (b) and the mixture of hLYPD8 and a gradient dose of flagella (c) or bacterial bodies (d) from P. mirabilis. e, $\mathbf{f}$ Motility of $P$. mirabilis in semisolid agar with the hLYPD8 protein or a control sample (a purified sample of non-transfected HEK293T cell lysate). Representative photos were shown (e). The radii of motility halos were measured at $4 \mathrm{~h}$ (f). Data are mean \pm s.d. ( $n=6$ per group). ${ }^{* *} p<0.01$ 
hLYPD8 by using the Pichia GlycoSwitch system [11]. This system uses the Pichia pastoris SuperMan ${ }_{5}$ strain, a methylotrophic yeast, which has strong promoters to drive the expression of a foreign gene. Moreover, it is a genetically modified strain that enable the production of large amounts of human-like glycosylated proteins with an easier technique and lower cost than other eukaryotic systems. Our previous mouse study revealed that the soluble form of mLypd8, shed from intestinal epithelial surface, acts on intestinal bacteria. Therefore, we constructed a soluble hLYPD8 expression vector by inserting a FLAG-tagged hLYPD8 sequence without a Cterminal signal sequence to the original Pichia GlycoSwitch vector. Recombinant hLYPD8 protein purified from the culture supernatant of $P$. pastoris transformed with the hLYPD8 expression vector was analyzed by SDS-PAGE and western blot analysis (Fig. 3a, b). Two bands for soluble hLYPD8 protein were observed at around the 50 and $30-\mathrm{kDa}$ positions. These analyses suggested that the purified soluble hLYPD8 protein solution included about $50 \mathrm{kDa}$ molecular weight of completely glycosylated hLYPD8 protein and $30 \mathrm{kDa}$ molecular weight of partially glycosylated hLYPD8 protein. We next tested whether soluble hLYPD8 protein generated from $P$. pastoris was $\mathrm{N}$-glycosylated, like GPIanchored hLYPD8 protein generated by the mammalian cell expression system. The treatment of PNGaseF reduced the molecular weight of soluble hLYPD8 protein, indicating that soluble hLYPD8 protein generated by the Pichia GlycoSwitch system is $N$-glycosylated (Fig. 3c).

\section{Functions of the hLYPD8 protein generated by a Pichia} pastoris expression system

We next examined the functions of soluble hLYPD8 protein generated by the $P$. pastoris expression system. We analyzed the binding of soluble hLYPD8 protein to several kinds of intestinal bacteria by an ELISA assay. We found that soluble hLYPD8 protein showed the stronger binding to $P$. mirabilis and E. coli, compared with the other non-flagellated bacteria (Fig. 4a). We then analyzed whether soluble hLYPD8 protein binds to flagella of $P$. mirabilis by the ELISA and pull-down assays (Fig. $4 \mathrm{~b}-\mathrm{d}$ ). The results of both binding assays revealed that soluble hLYPD8 protein binds to flagella of $P$. mirabilis with high affinity. Subsequently, we analyzed the effect on the motile activity of bacteria. Soluble hLYDP8 protein remarkably inhibited the swarming ability of $P$. mirabilis in a dose-dependent manner (Fig. $4 \mathrm{e}-\mathrm{g}$ ). Moreover, soluble hLYPD8 protein also inhibited the motility of E. coli (Fig. 4h, i). These data clearly demonstrated that highly glycosylated soluble hLYPD8 protein generated by the $P$. pastoris expression

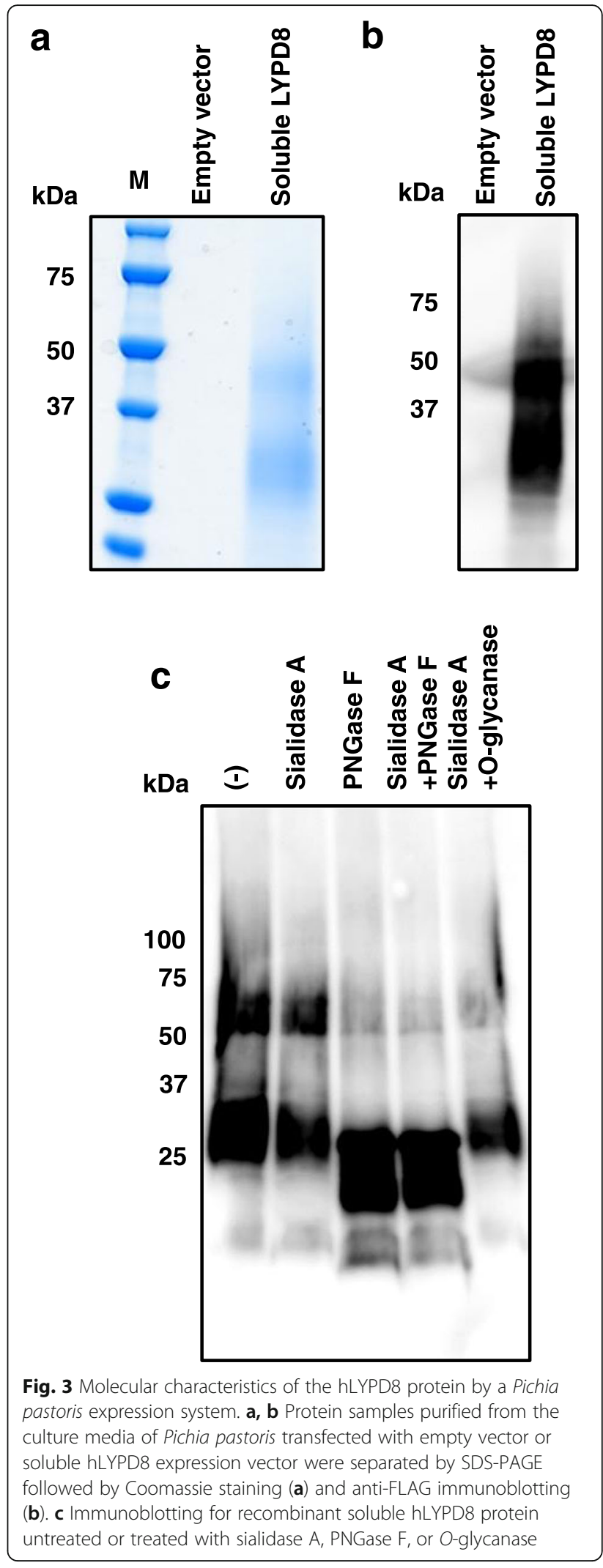



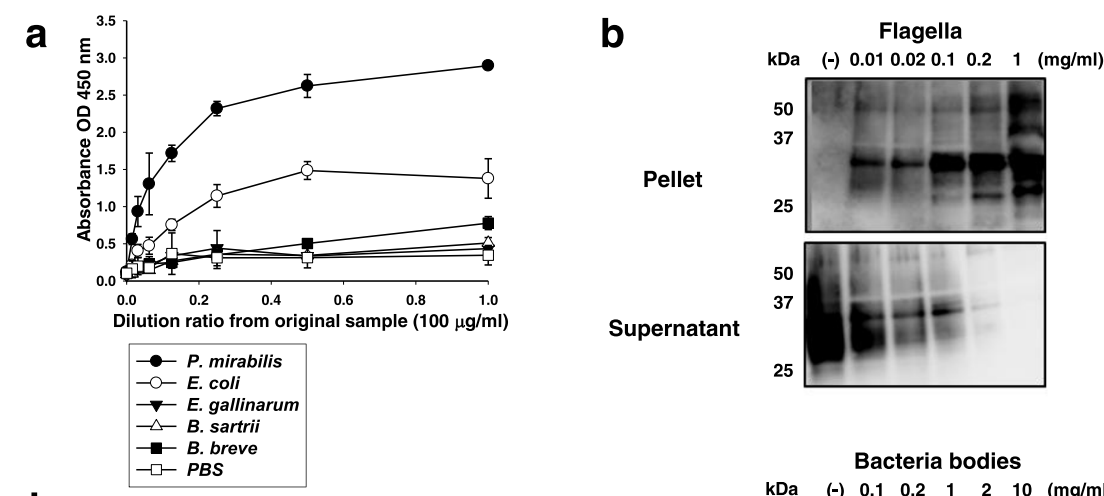

d

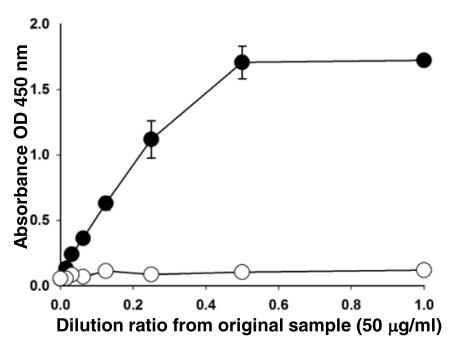

C

Bacteria bodies
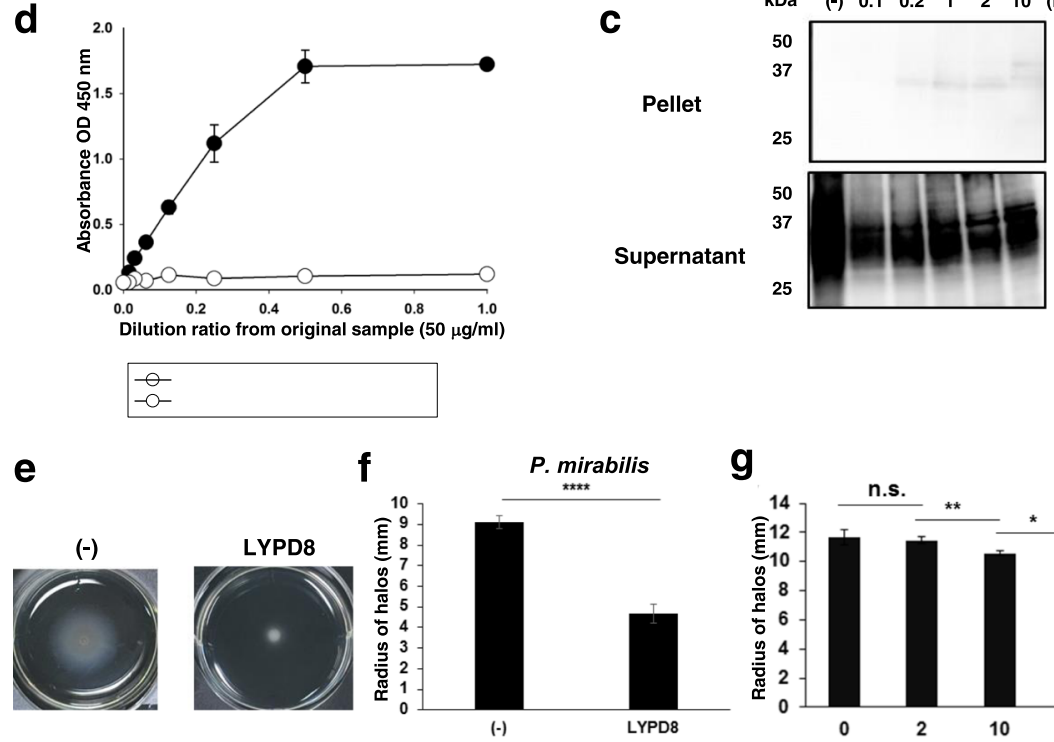

g

h

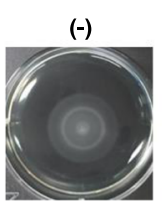

LYPD8

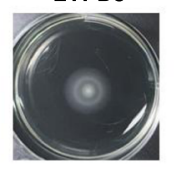

i

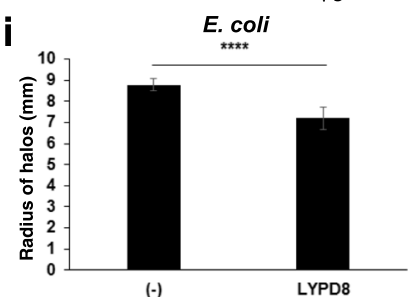

Fig. 4 Function of the hLYPD8 protein generated by a Pichia pastoris expression system. a ELISA assay for binding of soluble hLYPD8 protein from $P$. pastoris to the indicated species of intestinal bacteria. $\mathbf{b}, \mathbf{c}$ Immunoblot analysis with anti-FLAG antibody for the supernatant and pellet of the mixture of soluble hLYPD8 protein and a gradient dose of flagella (b) or bacterial bodies (c) from P. mirabilis. d ELISA assay of LYPD8 binding to flagella of $P$. mirabilis. e, $\mathbf{f}$ Motility of $P$. mirabilis in semisolid agar with or without soluble hLYPD8 protein. Representative photos are shown (e). The radii of motility halos were measured at $4 \mathrm{~h}(\mathbf{f})$. Data are mean \pm s.d. ( $n=6$ per group). $\mathbf{g}$ Motility of $P$. mirabilis in semisolid agar with a gradient concentration of soluble hLYPD8 protein. The radii of motility halos were measured at $4 \mathrm{~h}$. Data are mean \pm s.d. $(n=6$ per group). $\mathbf{h}, \mathbf{i}$ Motility of $E$. coli in semisolid agar with or without soluble hLYPD8 protein. Representative photos are shown (h). The radii of motility halos were measured at $4 \mathrm{~h}$ (i). Data are mean \pm s.d. $\left(n=6\right.$ per group). ${ }^{*} p<0.05,{ }^{* *} p<0.01$, ${ }^{* * *} p<0.001$. n.s. not significant

system suppresses the motility of flagellated bacteria by binding to the flagella.

\section{Discussion}

We previously demonstrated that mLypd8 contributes to the segregation of intestinal bacteria and intestinal epithelial cells through inhibiting bacterial invasion of colonic epithelia [9]. In this study, we characterized the
hLYPD8 protein. We found that the hLYPD8 protein generated by the mammalian cell expression system was a highly $N$-glycosylated GPI-anchored protein. In addition, the ELISA binding assay showed that the hLYPD8 protein preferentially bound to flagellated bacteria such as $P$. mirabilis and E. coli. The motility assay revealed that the hLYPD8 protein inhibited the motility of flagellated bacteria in a semi-agar plate. 
These results indicate that hLYPD8 has the same characteristics and functions as mLypd8.

Glycans of secretory or membrane proteins such as mucins, produced by intestinal epithelial cells, are critical for the maintenance of mucosal barriers [12, 13]. In the case of mLypd8, PNGase F treatment reduced the inhibitory function of mLypd 8 on intestinal epithelial cells, suggesting that $\mathrm{N}$-glycans are important in the function of Lypd8 [9]. $\mathrm{N}$-glycosylation varies across species and types of cells. The glycosylation in mammalian cells is the most suitable for mammalian glycosylated proteins to function appropriately. However, the ability of protein expression in mammalian cells is limited. Therefore, we generated soluble hLYPD8 protein by using a Pichia GlycoSwitch system, which makes it possible to generate large amounts of humanized-glycosylated protein at a relatively low cost. Both recombinant hLYPD8 proteins generated by mammalian cells and $P$. pastoris were highly $\mathrm{N}$-glycosylated, which suggests that both recombinant proteins include similar glycans. However, the molecular weight of both proteins was different, indicating that there seems to exist some dissimilarity in the glycosylation pattern between both proteins. Although the Pichia strain we used for heterologous protein expression has been engineered to generate more human-like product by mutating the yeast $\mathrm{OCH} 1$ gene which encodes $\alpha-1,6$-mannosyltransferase resulting in high mannose-type of $\mathrm{N}$-glycan and introducing heterologous enzyme activities [11], there remain many differences in glycosylation pathway between yeasts and mammalian cells [14]. Hence, the glycosylation pattern of Pichia pastoris generated protein is similar but not completely same as that of the protein produced by mammalian cells, and it is important to analyze the glycosylation pattern of both recombinant hLYPD8 proteins using mass spectrometry or lectin array analysis in the future. Despite the different glycosylation patterns, soluble hLYPD8 protein from $P$. pastoris showed a strong inhibitory effect for bacterial motility of flagellated bacteria. This result suggests that the difference in glycosylation between the mammalian cell expression system and the Pichia GlycoSwitch system does not affect the protein conformation influencing the protein activity. In addition, the purified soluble hLYPD8 protein solution included two forms of hLYPD8 proteins, fully or not fully glycosylated. Although soluble hLYPD8 protein contained a large amount of the immature form of the protein, it represented the inhibitory function against flagellated bacteria. Therefore, soluble hLYPD8 protein from $P$. pastoris can be used for further analyses of hLYPD8 protein function.

\section{Conclusion}

Collectively, we found that hLYPD8 has the same characteristics and functions as mLypd8, and we successfully generated the functional highly glycosylated hLYPD8 protein by using the $P$. pastoris expression system, which enables generation of large amounts of recombinant protein. However, it remains unclear how the LYPD8 protein inhibits the motility of flagellated bacteria. Therefore, it is crucial to analyze the mechanism by which the LYPD8 protein binds to the flagella and inhibits the flagellar motile activity. Nonetheless, there is no convincing therapeutic approach targeting the dysfunction of mucosal barriers in IBD patients. Thus, a challenge exists in examining whether the supplementation of the hLYPD8 protein can reduce the severity of intestinal inflammation by regulating the motile activity of flagellated bacteria, many of which are related to intestinal inflammation $[15,16]$.

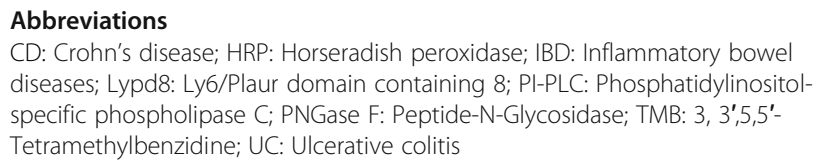

\section{Acknowledgements}

We thank T. Kondo and Y. Magota for their technical assistance and C. Hidaka for secretarial assistance.

\section{Funding}

This work was supported by grants from the Ministry of Education, Culture, Sports, Science and Technology of Japan, the Japan Agency for Medical Research and Development (to KT), Project MEET, Osaka University Graduate School of Medicine, Mitsubishi Tanabe Pharma Corporation, and Senri Life Science Foundation and Terumo Foundation for Life Science and Arts (to RO).

Availability of data and materials

All data generated or analyzed during this study are included in this published article.

\section{Authors' contributions}

$\mathrm{CH}$ and $\mathrm{RO}$ designed and performed the experiments, analyzed the data, and wrote the manuscript. KT supervised the study and revised the manuscript. All authors read and approved the final manuscript.

Ethics approval and consent to participate Not applicable.

Consent for publication

Not applicable.

Competing interests

The authors declare that they have no competing interests.

\section{Publisher's Note}

Springer Nature remains neutral with regard to jurisdictional claims in published maps and institutional affiliations.

\section{Author details}

'Department of Microbiology and Immunology, Graduate School of Medicine, Osaka University, Osaka 565-0871, Japan. ${ }^{2}$ WPI Immunology Frontier Research Center, Osaka University, Osaka 565-0871, Japan. ${ }^{3}$ Core Research for Evolutional Science and Technology, Japan Agency for Medical Research and Development, Tokyo 100-0004, Japan. 
Received: 30 August 2017 Accepted: 10 October 2017

Published online: 04 December 2017

\section{References}

1. Ayabe T, Satchell DP, Wilson CL, Parks WC, Selsted ME, Ouellette AJ. Secretion of microbicidal alpha-defensins by intestinal Paneth cells in response to bacteria. Nat Immunol. 2000;1(2):113-8.

2. Johansson ME, Phillipson M, Petersson J, Velcich A, Holm L, Hansson GC. The inner of the two Muc2 mucin-dependent mucus layers in colon is devoid of bacteria. Proc Natl Acad Sci U S A. 2008;105(39):15064-9.

3. Johansson ME, Larsson JM, Hansson GC. The two mucus layers of colon are organized by the MUC2 mucin, whereas the outer layer is a legislator of host-microbial interactions. Proc Natl Acad Sci U S A. 2011;108(Suppl 1): 4659-65.

4. Vaishnava S, Yamamoto M, Severson KM, Ruhn KA, Yu X, Koren O, Ley R, Wakeland EK, Hooper LV. The antibacterial lectin Reglllgamma promotes the spatial segregation of microbiota and host in the intestine. Science (New York, NY). 2011;334(6053):255-8.

5. Maynard CL, Elson CO, Hatton RD, Weaver CT. Reciprocal interactions of the intestinal microbiota and immune system. Nature. 2012;489(7415):231-41.

6. Ahmad R, Sorrell MF, Batra SK, Dhawan P, Singh AB. Gut permeability and mucosal inflammation: bad, good or context dependent. Mucosal Immunol. 2017;10(2):307-17.

7. Chang J, Leong RW, Wasinger V, Ip M, Yang M, Phan TG. Impaired intestinal permeability contributes to ongoing bowel symptoms in patients with inflammatory bowel disease and mucosal healing. Gastroenterology. 2017; 153(3):723-31

8. Johansson ME, Gustafsson JK, Holmen-Larsson J, Jabbar KS, Xia L, Xu H, Ghishan FK, Carvalho FA, Gewirtz AT, Sjovall H, et al. Bacteria penetrate the normally impenetrable inner colon mucus layer in both murine colitis models and patients with ulcerative colitis. Gut. 2014;63(2):281-91.

9. Okumura R, Kurakawa T, Nakano T, Kayama H, Kinoshita M, Motooka D, Gotoh K, Kimura T, Kamiyama N, Kusu T, et al. Lypd8 promotes the segregation of flagellated microbiota and colonic epithelia. Nature. 2016; 532(7597):117-21.

10. Wu S, Letchworth GJ. High efficiency transformation by electroporation of Pichia pastoris pretreated with lithium acetate and dithiothreitol. BioTechniques. 2004;36(1):152-4.

11. Jacobs PP, Geysens S, Vervecken W, Contreras R, Callewaert N. Engineering complex-type N-glycosylation in Pichia pastoris using GlycoSwitch technology. Nat Protoc. 2009;4(1):58-70.

12. Fu J, Wei B, Wen $T$, Johansson ME, Liu X, Bradford E, Thomsson KA, McGee S, Mansour L, Tong M, et al. Loss of intestinal core 1-derived Oglycans causes spontaneous colitis in mice. J Clin Invest. 2011;121(4): 1657-66.

13. Goto Y, Obata T, Kunisawa J, Sato S, Ivanov II, Lamichhane A, Takeyama N, Kamioka M, Sakamoto M, Matsuki T, et al. Innate lymphoid cells regulate intestinal epithelial cell glycosylation. Science (New York, NY). 2014; 345(6202):1254009

14. Vervecken W, Kaigorodov V, Callewaert N, Geysens S, De Vusser K Contreras R. In vivo synthesis of mammalian-like, hybrid-type N-glycans in Pichia pastoris. Appl Environ Microbiol. 2004;70(5):2639-46.

15. Garrett WS, Gallini CA, Yatsunenko T, Michaud M, DuBois A, Delaney ML, Punit S, Karlsson M, Bry L, Glickman JN, et al. Enterobacteriaceae act in concert with the gut microbiota to induce spontaneous and maternally transmitted colitis. Cell Host Microbe. 2010;8(3):292-300.

16. Rigottier-Gois L. Dysbiosis in inflammatory bowel diseases: the oxygen hypothesis. ISME J. 2013;7(7):1256-61.

\section{Submit your next manuscript to BioMed Central and we will help you at every step:}

- We accept pre-submission inquiries

- Our selector tool helps you to find the most relevant journal

- We provide round the clock customer support

- Convenient online submission

- Thorough peer review

- Inclusion in PubMed and all major indexing services

- Maximum visibility for your research

Submit your manuscript at www.biomedcentral.com/submit
) BioMed Central 